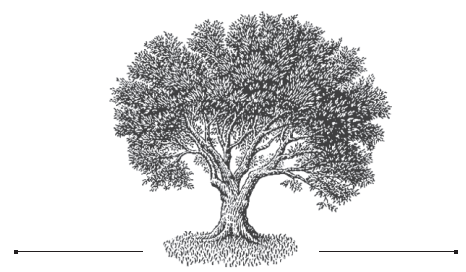

К основным

вопросам о

категории способа

глагольного действия

в русском языке

\section{Ильдико Падоши}

Университет им. Лоранда Этвёша

(Будапешт)

\section{On the Basic Problems of the Category of Aktionsart in the Russian Language}

\author{
Ildikó Pálosi \\ Eötvös Loránd University \\ (Budapest)
}

\title{
Резюме
}

Статья представляет собой обобщающую работу по вопросам о статусе, объему и границах категории способа глагольного действия в русском языке. По мнению автора, категория способа действия является семантико-словообразовательной категорией, включающей глаголы с формальным показателем модификации значения мотивирующего глагола за исключением глаголов движения. Категория способа действия входит в более обширную категорию аспекта в качестве ее лексико-семантического уровня. От сферы словообразования категория способа действия отграничивается регулярностью образования глаголов.

\section{Ключевые слова}

русский язык, глагол, способ действия, семантика, словообразование

\section{Abstract}

The article summarizes the basic questions of aktionsart (the status, content, and borders of the category) in the Russian language and describes the most relevant views on the problem. In the author's opinion, the category of aktionsart is a semantic-word formation category, one that includes motivated verbs with formal markers of semantic change of the base verb, except for verbs of motion. Taking into consideration that word formation models are polysemic, the verb classes of aktionsart can be specified not by formal factors but by semantic ones. Consequently, the content of 
the category of aktionsart is determined by word formation and semantics together. Another key problem is the connection between the category of aktionsart and category of grammatical aspect and the sphere of word formation. The author joins the opinion of those linguists who consider aktionsart to be the lexical level of the macrocategory of aspect. The category of aktionsart is separated from the sphere of word formation by the regularity of verb formation. Regarding this criteria, as the author suggests, some verb formation models of low regularity should not be acknowledged as verb classes of aktionsart.

Keywords

Russian language, verb, aktionsart, semantics, word formation

\section{1. Введение}

Настоящая статья представляет собой обобщающую работу по фундаментальным вопросам категории способа глагольного действия (в дальнейшем - СД) в русском языке, в ней сделана попытка дать ответы на следующие вопросы:

- Каков статус категории СД?

- Каков ее объем и как можно ее отграничить от других категорий?

- Как продуктивность образования определяет объем и классификацию СД?

Как известно, понятие способа действия (Aktionsart) было введено в 1908 г. шведским языковедом С. Агреллем, который впервые обратил внимание на важность разделения категории вида и категории способа действия. Противопоставление вида и СД он сформулировал следующим образом:

“Под способом действия (Aktionsart) я подразумеваю не две основные категории славянского глагола, не формы, обозначающие незаконченные и законченные действия (имперфективный и перфективный глагол), - эти категории я называю видами (Aspekte). Термином способ действия я обозначаю те до сих пор почти вовсе не привлекавшие внимания и тем более никем не классифицировавшиеся семантические функции приставочных глаголов (а также некоторых бесприставочных глаголов и суффиксальных образований), которыеуточняют, как совершается действие, обозначают способ его осуществления” [АгРЕлль 1962: 36].

Не входя в детали раннего периода изучения СД, отметим только, что значительный вклад в формирование данного понятия был внесен работами [ШАХмАтов 2001; ПотЕБНя 1941; КошмидеР 1962; ВиногРАдов 2001]. Наиболее существенными нам представляются научные результаты, опубликованные в более поздних работах [ИсАчЕнко 1960; 
БОНДАРКО, БУЛАНИН 1967; АвИЛОВА 1976; ШЕЛЯКИН 1983; 2008; МАСлов 1984; 2004; КРЕКИЧ 1989; 1997; РЯНСКАЯ 2002; KRÉKITS, JÁSZAY 2008; ПЕтрухинА 2009]. Существует ряд исследований, включающих компаративный аспект изучения проблемы, напр. на материале венгерского и русского языков [ДЕжё 1984]; на материале финского и русского языков [ТоммолА 1986]; на материале испанского и русского языков [ГорьоВА 1996; 1999]; на материале французского и русского языков [РянСКАЯ 2003]; на материале немецкого и русского языков [РАХмАНКуловА 2004]; на материале немецкого, польского и венгерского языков [PÁtrovics 2004]; на материале нескольких славянских языков [KRÉKITS, JÁSZAY 2008]. Вопрос о категории СД в венгерском языке затронут в работе [KIEFER 2006].

\section{2. Статус категории СД \\ 2.1. Отношение категории СД к категории вида}

Вопрос о способах действия традиционно рассматривается в тесной связи с категорией вида. Это не случайно, поскольку категория СД и категория вида представляют собой составляющие компоненты сферы аспектуальности. Поясним наше утверждение, опираясь на историю исследования проблематики.

В общеизвестном определении категории вида, сформулированном А. М. Пешковским, согласно которому “категория вида обозначает, как протекает во времени или как распределяется во времени тот процесс, который обозначен в основе глагола” [Пешковский 2001: 105], СД еще не были отделены от вида. Исследователь, по всей вероятности, не был знаком с процитированным выше высказыванием С. Агрелля. Дефиниция А. М. Пешковского неоднократно подвергалась критике и дополнению со стороны многих лингвистов.

В последнее время среди аспектологов стала общепринятой позиция, согласно которой процитированное выше определение А. М. Пешковского характеризует более широкую категорию аспектуальности, охватывающую категории вида и СД. В сфере аспектуальности Ю. С. Маслов различал два компонента: лексическую и грамматическую аспектуальность, которые он называл аспектуальными классами и грамматической категорией вида. Аспектуальные классы выделяются по признаку предельности/непредельности и делятся на более мелкие аспектуальные подклассы, иными словами, на способы глагольного действия [МАслов 1984: 10-14; 2004: 31-33]. В своей более ранней работе Ю. С. Маслов высказал мнение о том, что среди глаголов, относящихся к тому или иному СД, выделяется 3 группы: 1) глаголы perfectiva tantum; 2) глаголы imperfectiva tantum; 3) глаголы, выступающие в обоих 
видах [МАслов 1962: 12] ${ }^{1}$. Этим утверждением он критиковал концепцию А. В. Исаченко, согласно которой одним из признаков СД является видовая несоотносительность [ИСАЧЕНКо 1960: 217]. Промежуточной категорией между видом и СД Ю. С. Маслов считает категорию предельности/непредельности [МАслов 1984: 11; 2004: 29-30]. Эта идея находит отражение в работах [БондАРКо, БулАнин 1967: 29; ШЕляКИн 1983: 178; 2001: 88; 2008: 128; КРЕКИч 1989: 11-12]. МЫ, со своей стороны, согласны с Ю. С. Масловым в том, что не все глаголы, относящиеся к тому или иному СД, являются одновидовыми.

Отношение категории вида к категории аспектуальности М. А. Шелякин определяет следующим образом: “аспектуальность [. . ] является универсальной языковой категорией, которая отражает всеобщую картину проявления действия во времени, а категория вида как одна из разновидностей аспектуальности характерна только для славянских языков” [Шелякин 2008: 25]. На его взгляд, аспектуальность входит в более обширную категориальную область с семантикой характера способа осуществления действия - в категорию характеризации глагольного действия. В рамках данной области М. А. Шелякин различает аспектуальную и неаспектуальную характеризацию. Под первым типом он подразумевает саму аспектуальность, а для терминологического обозначения неаспектуальной характеризации он предлагает употреблять термин, введенный С. Агреллем, - “акционсарт” [Шелякин 2008: 19]. Со своей стороны, мы полагаем, что, поскольку данный термин и производные от него прилагательное акциионсартный и существительное акциионсартность связаны с более узкой категорией СД, увеличение сферы его употребления может привести к смешению понятий. В рамках категории аспектуальности М. А. Шелякин выделяет четыре уровня: грамматический, лексическо-семантический и контекстуальный уровни, а также уровень характера и типа действия. Грамматическим уровнем он называет категорию вида. Лексико-семантический уровень аспектуальности образуют аспектуальные СД или аспектуальные разряды предельных/непредельных глаголов (термин М. А. Шелякина). Контекстуальный уровень аспектуальности представлен адвербиальными словами и словосочетаниями (типа долго, три раза, вдруг и т. д.), сочетаниями спрягаемых форм глагола в составе сложного предиката (типа начал петь), сочетаниями глаголов с дополнениями в определенных падежных формах (типа съесть весь суn, noесть супа) и синтаксическими конструкциями (типа Чем больше..., тем больше...). Характером действия М. А. Шелякин называет "те признаки лексических значений, которые показывают формы проявления способов действия” [Шелякин 2008: 39] (напр. постепенное

1 Подобная идея представлена в статье [НЕттеБерг 1962: 65-67]. 
накопление результата или постепенное приближение к результату), а типом действия - семантическую зону, охватываемую аспектуальным СД [ТАМ ЖЕ: $30-40]^{2}$.

Существенной для нашей темы является статья И.-Э. С. Рахманкуловой, которая, разъясняя понятия “аспект”, “акционсарт” и “вид” в русской и немецкой аспектологии, указывает на изложенную выше точку зрения М. А. Шелякина и утверждает, что термин “способ глагольного действия” употребляется для обозначения подтипов понятия предельности/непредельности [РАхмАнкуловА 2004: 15-26]. В отличие от категории вида, категорию СД И.-Э. С. Рахманкулова считает лексико-семантической категорией, которая служит “скорее возможности проявления нюансированности лексического значения” глаголов [РАХмАнкуловА 2004: 26].

Категория аспекта явилась объектом сравнительного анализа в целом ряде лингвистических работ. Кроме вышеупомянутой статьи И.-Э. С. Рахманкуловой нельзя оставить без внимания работу В. А. ПлунгянА [1997], посвященную типологическому анализу аспекта на материале русского языка и языка догон. Необходимо отметить его замечание о том, что аспект в естественных языках редко выражается чисто словоизменительными противопоставлениями, чаще он “превращается в словоклассифицирующую грамматическую категорию” (см. категорию вида в славянских языках) либо выражается разными словообразовательными группами (см. способы действия) [Плунгян 1997: 179]. В русском языке аспект манифестируется обоими способами. Ценными являются рассуждения В. А. Плунгяна в области классификации аспектуальных категорий. Вслед за И. А. Мельчуком в рамках категории аспектуальности он выделяет три аспекта: количественный, фазовый и результативный. Количественный аспект ситуации проявляется в ее одноактности/многоактности. Основными семантическими противопоставлениями этой зоны считаются итератив (полностью повторяющиеся ситуации), мультипликатив (единые множественные действия) и дистрибутив (действия, распространяющиеся на несколько объектов или совершаемые несколькими субъектами). Фазовый аспект охватывает длящиеся и недлящиеся ситуации. В. А. Плунгян относит к ним мгновенные ситуации (типа найтu), пунктив (мысленно сжатые ситуации), инхоатив (начало действия), континуатив (продолжение действия),

2 Заметим, что термин “аспектуальный способ действия” был введен М. А. Шелякиным в переработанном и дополненном издании 2008 г. его фундаментальной для аспектологии монографии “Категория вида и способы действия русского глагола” 1983 г. В оригинальном варианте, как показывает и название работы, употребляется термин “способ действия”, который считается традиционно принятым и самым распространенным наименованием данной категории. В “Функциональной грамматике русского глагола” [Шелякин 2001] автор предпочитает термин “аспектуальный разряд”. 
терминатив (прекращение ситуации), дуратив (нерезультативные, длящиеся ситуации) и прогрессив (длящаяся в момент речи ситуация). Результативный аспект включает комплетив (ситуации, включающие достижение результата), результатив (ситуация, возникшая после достижения результата) и перфект (ситуация, являющаяся результатом действия). Эти аспектуальные значения могут пересекаться с неаспектуальными значениями, например, со значением интенсивности (см. глаголы типа расплакаться: 'начало' + 'повышенная интенсивность', покашливать 'итеративность' + 'сниженная интенсивность' и т. д.) [Плунгян 1997: 179-186]. Из тщательного анализа В. А. Плунгяна явствует, что перечисленные аспекты могут быть представлены категорией вида и/или глаголами разного способа действия.

Функциональная грамматика рассматривает СД в рамках функционально-семантического поля аспектуальности. Морфологическое ядро поля формирует категория вида, а СД относятся к периферии поля. СД формируют категорию предельности/непредельности, являясь ее конкретными, детализованными значениями. Они различаются между собой и по специфике своего выражения, и по указанию на тот конкретный характер предельности/непредельности действия, который определяет тип его протекания: результативность/нерезультативность, временной предел, предел интенсивности и т. д. Выделяется группа общерезультативных глаголов, к которым в принципе могут относиться все глаголы совершенного вида с результативным значением [БондАРко 1987]. Такой подход был представлен М. А. Шелякиным еще до издания указанного тома серии “Теория функциональной грамматики”.

\section{2. Отношение категории СД к области словообразования}

Категорию СД следует отграничить не только от категории вида, но и от сферы словообразования. По мнению Н. С. Авиловой, СД - это явление, стоящее на границе между словообразованием глагола и его видообразованием, но все же она понимает категорию СД как семантико-словообразовательные группы глаголов [АвиловА 1976: 259]. Такой взгляд отражается в работах [ШАнский, Тихонов 1981: 180; ДЕжё 1984: 76; ТомМОЛА 1986: 1; ЗАЛИЗНЯк, ШМЕЛЕВ 1997: 87; КРЕКИЧ 1997: 23-36; КЛИМОнов 2003: 110]. По утверждению Анны А. Зализняк и А. Д. Шмелева, отграничение категории СД от сферы словообразования можно провести на основании регулярности образования. Однако и вышеупомянутые авторы считают этот критерий довольно зыбким, по причине многозначности русских приставок [ЗАлизняк, ШмЕлЕв 1997: 87]. Примеры (1), (2) и (3) иллюстрируют отношение/неотношение одного глагола к сфере СД в силу своей многозначности. 
(1) Дважды в кабинет заходил человек в белом халате (Б. Акунин. Особые поручения);

(2) Войти в город колонной, с развернутым знаменем и барабанным боем, я - впереди, на Гульноре, - распаляясь, заходил по кабинету Соболев (Б. Акунин. Турецкий гамбит);

(3) Речь в боксах редко шла о тонкостях пилотирования, чаще разговор заходил о повышенной нагрузке на те или иные узлы (К. Качнов. Спокойствие, только спокойствие // “Формула”, 2001, пример НКРЯ: http:// www.ruscorpora.ru/).

В примере (1) употреблен глагол, относящийся к лексико-семантическому классу глаголов движения, т. е. в этом случае приставка за- вносит значение направленности внутрь какого-либо помещения. В предложениях (2) и (3) приставкой з $a$ - передается значение начальной фазы действия, поэтому глагол заходить в данном значении является представителем начинательного СД. Отношение глаголов движения к категории СД является спорным вопросом, см. об этом ниже под пунктом 3.

В работах [РÁtRovics 2004: 37; ВАРАКСИН 2005: 144; ШАРАНдин 2005: 139; ПЕтрухинА 2009: 93] высказано мнение, согласно которому категория СД считается словообразовательной категорией, в них нет отграничения категории СД от словообразования. Заслуживает особого внимания интерпретация А. Л. Шарандина, который считает СД словообразовательно-модификационной категорией, имеющей парадигму словообразовательных форм. Связующими элементами трансформ парадигмы, по мнению исследователя, являются мотивация и инвариантное значение акционсартности [ШАРАндин 2005: 138].

Другая крайность научных взглядов представлена в работах [MACлов 1984: 8-15; 2004: 27-34; БоНДАРКО, БУЛАНИн 1967: 12-28; БондАРко 1987: 63-85; ШЕлякин 1983: 157-196; 2001: 88-93; 2008: 123-167; РянскАя 2002/1; 2002/2; ГАшКОВА 2003; РАхмАнКуловА 2004], в которых категория СД интерпретируется как семантическая категория.

\section{3. Объем и границы категории СД}

Вопрос о статусе категории СД тесно связан с проблемой его объема и границ. Вопрос о том, охватывает ли категория СД все глаголы или только их ограниченный круг, остается до сих пор нерешенным.

Напомним, что под СД С. Агрелль подразумевал семантические функции глаголов с формальными показателями, уточняющими характер протекания действия [АгРЕлль 1962: 36]. Кардинальное изменение в понятие СД было внесено Ю. С. Масловым, который предложил рассматривать СД независимо от их формальной характеристики, утверждая, что одни СД обладают определенными формальными признаками - 
это так называемые “характеризованные СД”, а другие - “нехарактеризованные СД” - не имеют формальных показателей. В третью, промежуточную, группу входят “непоследовательно характеризованные СД” [МАслов 1984: 14; 2004: 33]; см. еще [БондАрко, БулАнин 1967: 12-28; БондАРко 1987: 63-85]. При таком понимании категория СД, подобно категории вида, охватывает всю глагольную лексику. Концепции Ю. С. Маслова придерживаются авторы работ [ШЕлякин 1983: 157-196; 2001: 88-93; 2008: 123-167; РЯНСКАЯ 2002; ГАШКОВА 2003; РАХМАНКУЛоBA 2004].

Другие лингвисты не порвали с традицией, восходящей к С. Агреллю. Среди них выделяется работа [ИсАчЕнко 1960], в которой автором различаются “совершаемости” и “характеры глагольного действия”. Признаками “совершаемостей” являются: 1) отсутствие видовой пары; 2) выражение особенности лексического значения формальными показателями - приставками или суффиксами. Характер действия - это те общие значения глаголов, которые не выражаются формальными маркерами 3 [ИсАчЕнко 1960: 218; 301]. Концепция автора была подвергнута жесткой критике Ю. С. Масловым и А. В. Бондарко, настаивавшими на объединении глаголов с формально выраженным значением действия и с формально не выраженным значением действия в одну категорию. Несмотря на то что попытка А. В. Исаченко ввести термин “совершаемость” в лингвистический узус как новое научное понятие оказалась безуспешной и его взгляд об исключении парных глаголов из категории СД представляется далеко не бесспорным, его стремление следовать за традиционной русской грамматикой нашло сторонников. Для развития теории СД представляется немаловажной монография Н. С. Авиловой, в которой при определении сущности СД подчеркнута обязательность формального выражения модификации значения действия, обозначенного глагольной основой, и ввиду этого автор считает категорию СД семантико-словообразовательной [АвиловА 1976: 263].

Оригинальная точка зрения введена в рассматриваемую нами проблематику П. А. Соболевой, расширяющей состав префиксов, участвующих в образовании СД. Рабочей гипотезой автора является возможность включения приставок с пространственным значением в число формантов того или иного СД [СоБолевА 1983: 48; 1984: 97]. Из этого следует,

3 Подробный анализ характеров глагольного действия проведен Е. В. Горбовой на материале испанского и русского языков [ГорьовА 1996: 87-92; 1999]. Под характерами глагольного действия автором понимаются аспектуальносемантические группы, включающие глаголы независимо от формальной манифестации их значения, классификация которых должна иметь универсальный характер. В силу этого в классификацию вовлекаются все значения, относящиеся к качественной и количественной аспектуальности. 
что к категории СД она причисляет абсолютно все приставочные глаголы и что глаголы движения как лексико-семантический разряд получают статус СД. В силу того что П. А. Соболева придерживается условия морфологической маркированности модификации глагольного значения, но в категорию СД включает и глаголы движения, - предложенную ею концепцию можно считать своеобразным гибридом идей Ю. С. Маслова и Н. С. Авиловой. Ф. Кифер подчеркивает, что приставка, являющаяся формантом СД, может выражать значение, возникшее путем грамматикализации, исключительно независимое от первичного обстоятельственного значения [KIEFER 2006: 143-145]. Относительно границ категории СД, кроме критерия наличия форманта непространственного значения модификации семантики основного глагола Ф. Кифер определяет принцип необходимости регулярности (продуктивности) образования. Под продуктивностью им понимается возможность распространения той или иной группы СД новыми глагольными трансформами [KIEFER 2006: 149]. Критерий продуктивности образования заставляет исследователей отказаться от выделения малообъемных групп глаголов, которое превращает классификацию СД в семантическое подразделение (раздробление) лексики. Подобное мнение высказывается в работе [ЗАлизняк, ШмЕлЕв 1997: 87].

Многочисленные расхождения во взглядах о статусе, объеме и границах категории СД показывают, что ее теоретические параметры имеют ряд неясностей и недоработок. Понятие СД, как нам кажется, еще не до конца выкристаллизовалось. Исходя из изложенных выше концепций, можно установить пять интерпретаций категории СД:

- семантическая категория, охватывающая все глаголы (Ю. С. Маслов, А. В. Бондарко, Л. Л. Буланин, Х. Томмола, М. А. Шелякин, Э. М. Рянская, М. Г. Гашкова, И.-Э. С. Рахманкулова);

- семантико-словообразовательная категория, включающая все глаголы с формальным показателем модификации значения мотивирующего глагола (П. А. Соболева);

- семантико-словообразовательная категория, охватывающая глаголы с формальным показателем модификации значения, отличающегося от пространственного (Н. С. Авилова, Н.М. Шанский, А. Н. Тихонов, Л. Дежё, Анна А. Зализняк, А. Д. Шмелев, Й. Крекич, В. Д. Климонов, Ф. Кифер);

- семантико-словообразовательная категория, охватывающая одновидовые глаголы с формальным показателем модификации значения, отличающегося от пространственного (А. В. Исаченко);

- словообразовательная категория (П. Патрович, Л.А. Вараксин, А. Л. Шарандин, Е. В. Петрухина). 
Наша гипотеза о категории СД опирается на трактовку Н. С. Авиловой. Мы полагаем, что категорию СД невозможно рассматривать как грамматическую, ввиду того что выражение того или иного СД не является обязательным. Мы согласны с теми исследователями, которые считают СД семантико-словообразовательной категорией. Это следует из принятого нами положения об обязательности морфологической выраженности модификации значения основного глагола. Однако глаголы, относящиеся к тому или иному СД, объединяются не исключительно тождественными формальными маркерами, они связываются и общим значением. Следует подчеркнуть, что к одному СД могут причисляться глаголы с разными формантами на основе общности их семантики. Так, одноактный СД включает в себя глаголы с суффиксом -ну- типа прыгнуть, глаголы с суффиксом - ану- типа долбануть, глаголы с префиксом c- типа сглупить, а также глаголы с приставкой про- типа проскрипеть.

При классификации СД ${ }^{4}$ следует стремиться к балансу между семантической и словообразовательной характеристиками глагольных групп. С одной стороны, классификация должна отражать нюансированность категории СД, с другой стороны, она не должна быть слишком раздробленной. При классификации СД также необходимо принять во внимание продуктивность словообразовательной модели. Это утверждение относится как к выделению определенных классов, так и к их наполненности.

Следуя принципу необходимости регулярности образования, мы предлагаем исключить некоторые типы глаголов из категории СД:

- Глаголы с формантом про-...-ну-... типа простирнуть, относящиеся к уменьшительно-смягчительному СД [РГ-І 1980: 599];

- Глаголы с формантом вы-...-ыва-/-ива-... типа выплясывать, выделывать, относящиеся к прерывисто-смягчительному СД [ЗАлизНЯК, ШМЕЛЕВ 1997: 104];

- Глаголы с формантом от-...-ыва-/-ива-... типа отплясывать, откальвать <номера>, относящиеся к интенсивно-кратному СД [РГ-I 1980: 601];

- Глаголы с формантом за-...-ьвва-/-ива-... типа запузыривать, относящиеся к тому же СД [АвиловА 1976: 299].

4 Несмотря на многочисленную попытку классифицировать СД, их точный состав до сих пор не установлен. Наиболее существенными представляются классификации в работах [ИСАЧЕНКо 1960: 224-294; БоНдАРКО, БулАНИН 1967: 14-28; АвиловА 1976: 270-316; РГ-І 1980: 596-604; БондАРко 1987: 73-85; ШАНСКИЙ, Тихонов 1981: 180-184; ШЕлякин 1983: 180-196; 2008: 141-167; ЗАЛИЗНЯК, ШМЕЛЕВ 1997: 89-107; КРЕКИЧ 1997: 24-36; ПОПОВА 1997: 163-170; Климонов 2003: 111-119].

5 Н. С. Авилова для обозначения интенсивно-кратного СД употребляет термин “осложненно-интенсивный СД” [АвиловА 1976: 298-299]. 
Нам кажется целесообразным воздержаться от выделения таких малообъемных СД, как неумеренно-интенсивный СД, реализующийся конфиксом о-/об-/обо-...-ся (обкушаться, объесться, обожраться) [Трошкина 2001: 13]. Данная группа глаголов характеризуется семантической однородностью мотивирующих глаголов, поскольку лексическим значением всех перечисленных выше глаголов является питание. Дериваты указывают на чрезмерное проявление этого действия: 'съесть слишком много, лишнее'. Различие между глаголами заключается лишь в стилистическом оттенке: объесться и обкушаться относится к разговорному стилю, обожраться - к просторечию.

\section{4. Итоги}

Мы полагаем, что категория СД является семантико-словообразовательной категорией, входящей в более широкую категорию аспекта в качестве ее лексическо-семантического уровня. Учитывая, что словообразовательные модели не однозначны, отдельные классы глаголов определяются не на формальной, а на семантической основе. Следовательно, сущность категории СД определяется словообразованием и семантикой вместе.

Категория СД включает глаголы с формальным показателем модификации значения мотивирующего глагола, но глаголы движения остаются вне границ категории. Они формируют лексико-семантический разряд, имеющий свои внутренние закономерности и семантические нюансы. Глаголы движения играют значительную роль в формировании категории СД с диахронической точки зрения, но принимая во внимание, что их семантика направлена не на протекание и распределение действия во времени, мы считаем правомерным отказаться от их включения в категорию СД.

Критерий регулярности образования может сузить категорию СД за счет вытеснения глаголов малопродуктивного образования и малообъемных глагольных групп. Мы считаем необходимым рассмотреть существующие классификации с учетом этого принципа, чтобы получить более целостное представление о категории СД.

\section{Библиограсрия}

АвиловА 1976

Авилова Н. С., Вид глагола и семантика глагольного слова, Москва, 1976.

АГРЕлЛЬ 1962

АгРЕлль С., “О способах действия польского глагола”, в: Ю. С. МАСлов, ред., Вопросы глагольного вида, Москва, 1962, 35-37. 
БОНДАРКО 1987

БондАРко А. В., “Основания функциональной грамматики”, в: А. В. БондАРКо, ред., Теория функииональной грамматики. Введение. Аспектуальность. Временная локализованность. Таксис, Ленинград, 1987, 63-85.

БОНДАРКО, БУЛАНИН 1967 БондАРко А. В., БУЛАнИн Л. Л., Русский глагол, Ленинград, 1967.

ВАРАКСИН 2005

ВАРАКсиН Л. А., “Пространственные и непространственные значения русских глагольных приставок”, в: Н. К. ФлоровА, С. М. БЕЛяковА, ред., Пространство и время в языке, язык в пространстве и времени, Тюмень, 2005, 139-147.

ВИНОГРАДОВ 2001

ВиногРАдов В. В., Русский язык. Грамматическое учение о слове, Г. А. ЗолотовА, отв. ред., 4-е изд., Москва, 2001.

ГАШКОВА 2003

ГАшковА М. Г., Средства репрезентации начинательного и смягчительного способов действия в немещком языке в сопоставлении с русским (автореф. дисс. [. . .] канд. филол. наук, Екатеринбург, 2003).

ГорьовА 1996

Горьова Е. В., Сопоставительный анализ категорий поля аспектуальности в русском и испанском языках и их речевой реализации (дисс. [. . .] канд.филол.наук., С.-Петербург, 1996).

\section{9}

ГорьовА Е. В., “Опыт разработки универсальной классификации характеров глагольного действия”, в: Материалы XXVIII международной научно-методической конференци преподавателей и аспирантов, 16/1, С.-Петербург, 1999, 7-13.

ДЕжЁ Л. 1984

ДЕжё Л., Типологическая характеристика русской грамматики в сопоставлении с венгерской, Будапешт, 1984.

ЗАЛИЗНЯК, ШМЕЛЕВ 1997

ЗАлизняк Анна А., ШмелЕв А. Д., Лекциии по русской аспектологии (= Slavistische Beiträge, 353), München, 1997.

ИСАЧЕНКО 1960

ИСАченко А. В., Грамматический строй русского языка в сопоставлении с словацким, 2, Братислава, 1960.

Климонов 2003

Климонов В. Д., “Способы действия в русском и немецком языках”, Studia Rossica Posnaniensia, 31, 2003, 109-119.

КОШМИДЕР 1962

КошмидеР Э., “Очерк науки о видах польского глагола. Опыт синтеза”, в: Ю. С. МАслов, ред., Вопросы глагольного вида, Москва, 1962, 105-107.

КРЕКИЧ 1989

КРекич Й., Семантика и прагматика временно-предельных глаголов, Будапешт, 1989. 1997

КРекич Й., Педагогическая грамматика русского глагола. Семантика и прагматик, Szeged, 1997.

МАслов 1962

МАслов Ю. С., “Вопросы глагольного вида в современном зарубежном языкознании”, в: Ю. С. МАслов, ред., Вопросы глагольного вида, Москва, 1962, 7-32. 
МАслов Ю. С., Очерки по аспектологии, Ленинград, 1984. 2004

МАслов Ю. С., Избранные труды: Аспектология. Общее языкознание, Москва, 2004.

НеTтЕБеРГ 1962

НЕТтЕБеРГ К., “Способы действия, представленные в обоих видах и только в одном”, в: Ю. С. МАСлов, ред., Вопросы глагольного вида, Москва, 1962, 65-67.

ПЕТРУХИНА 2009

Петрухина Е. В., Русский глагол: категории вида и времени (в контексте современных лингвистических исследований), Москва, 2009.

ПЕшковский 2001

ПЕшковский А. М., Русский синтаксис в научном освещении, 8-е изд., Москва, 2001.

Плунгян 1997

Плунгян В. А., “Вид и типология глагольных систем”, в: ЧертковА М. Ю., ред., Труды аспектологического семинара филологического факультета МГУ им. М. В. Ломоносова, Москва, 1997, 173-190.

Попова 1997

ПоповА Т. В., “Пересекаемость лексико-семантических групп и лексикограмматических классов слов”, в: Л. Г. БАБЕнко, ред., Русская глагольная лексика: пересекаемость парадигм. Памяти Эры Васильевны Кузнецовой, Екатеринбург, 1997, 147-239.

ПотеБня 1941

ПотеБня А. А., Из записок по русской грамматике, 4, Ленинград, 1941.

РАХМАНКУЛОВА 2004

РАХмАнКУловА И.-Э. С., “К вопросу о теории аспектуальности”, Вопросы языкознания, 1, 2004, 3-28.

РГ-I 1980

Шведова Н. Ю., ред., Русская грамматика, 1, Москва, 1980.

РЯНСКАЯ 2002

Рянская Э. М., Способы действия в когнитивном аспекте, С.-Петербург, 2002.

СобоЛЕВА 1983

СоболевА П. А., “Опыт упорядочения способов глагольного действия”, в: Аспектуальные и темпоральные значения в славянских языках. Материалы заседания комиссии по изучению грамматического строя славянских языков МКС, Москва, 1983, 46-52. 1984

СоболЕвА П. А., “Способы глагольного действия и словообразовательные разряды глаголов”, в: В. Н. ЯРцЕвА, ред., Слово в грамматике и словаре, Москва, 1984, 93-101.

ТомМолА 1986

Томмола Х., “Аспектуальность в финском и русском языках”, Neuvostoliittoinstituutin vuosikirja, 28, 1986.

ТрошкинА 2001

Трошкина А. Н., Номинативный аспект категории интенсивности действия в разноструктурных языках (на материале русского и английского языков) (автореф. дисс. [...] канд. филол. наук, Саратов, 2001).

ШАнский, Тихонов 1981

ШАнский Н. М., Тихонов А. Н., Современный русский язык. Словообразование.

Морфология, 2, Москва, 1981. 
ШАРАНДИН 2005

ШАРАндин А. Л., “Способ глагола как особая формообразовательная категория русского глагола” в: Функционально-лингвистические исследования: сб. ст. в честь А. В. Бондарко, С.-Петербург, 2005, 133-141.

ШАХМАТОВ 2001

Шахматов А. А., Синтаксис русского языка, 3-е изд., Москва, 2001.

ШЕлякин 1983

ШЕлякин М. А., Категория вида и способы действия русского глагола, Таллин, 1983. 2001

Шелякин М. А., Функциональная грамматика русского глагола, Москва, 2001.

ШЕлякин 2008

Шелякин М. А., Категория аспектуальности русского глагола, Москва, 2008.

KIEFER 2006

KIEFER F., Aspektus és akcióminőség különös tekintettel a magyar nyelvre, Budapest, 2006.

KRÉKITS, JÁSZAY 2008

KRÉKITS J., JÁSZAY L., Szláv igeaspektus különös tekintettel az orosz nyelvre, Budapest, 2008.

PÁtrovics 2004

PÁtrovics P., Az aspektus története és tipológiája, Budapest, 2004.

\section{References}

Agrell' S., "O sposobakh deistviia pol'skogo glagola,” in: Iu. S. Maslov, ed., Voprosy glagol'nogo vida, Moscow, 1962, 35-37.

Avilova N. S., Vid glagola $i$ semantika glagol'nogo slova, Moscow, 1976.

Bondarko A. V., "Osnovaniia funktsional'noi grammatiki,” in: A. V. Bondarko, ed., Teoriia funktsional'noi grammatiki. Vvedenie. Aspektual'nost'. Vremennaia lokalizovannost'. Taksis, Leningrad, 1987, 63-85.

Bondarko A. V., Bulanin L. L., Russkii glagol, Leningrad, 1967.

Dezső L., Tipologicheskaia kharakteristika russkoi grammatiki v sopostavlenii s vengerskoi, Budapest, 1984.

Gorbova E. V., "Opyt razrabotki universal'noi klassifikatsii kharakterov glagol'nogo deistviia,” in: Materialy XXVIII mezhdunarodnoi nauchno-metodicheskoi konferentsii prepodavatelei $i$ aspirantov, 16/1, St. Petersburg, 1999, 7-13.

Issatschenko A. V., Grammaticheskii stroi russkogo iazyka v sopostavlenii s slovatskim, 2, Bratislava, 1960.

Kiefer F., Aspektus és akcióminôség különös tekintettel a magyar nyelvre, Budapest, 2006.

Klimonov V. D., "Sposoby deistviia v russkom i nemetskom iazykakh,” Studia Rossica Posnaniensia, 31, 2003, 109-119.

Koszmider E., "Ocherk nauki o vidakh pol'skogo glagola. Opyt sinteza,” in: Iu. S. Maslov, ed., Voprosy glagol'nogo vida, Moscow, 1962, 105-107.
Krékits J., Semantika i pragmatika vremenno-predel'nykh glagolov, Budapest, 1989.

Krékits J., Jászay L., Szláv igeaspektus különös tekintettel az orosz nyelvre, Budapest, 2008.

Maslov Iu. S., "Voprosy glagol'nogo vida v sovremennom zarubezhnom iazykoznanii," in: Iu. S. Maslov, ed., Voprosy glagol'nogo vida, Moscow, 1962, 7-32.

Maslov Iu. S., Ocherki po aspektologii, Leningrad, 1984.

Maslov Iu. S., Izbrannye trudy: Aspektologiia. Obshchee iazykoznanie, Moscow, 2004.

Netteberg K., "Sposoby deistviia, predstavlennye v oboikh vidakh i tol'ko v odnom," in: Iu. S. Maslov, ed., Voprosy glagol'nogo vida, Moscow, 1962, 65-67.

Pátrovics P., Az aspektus története és tipológiája, Budapest, 2004.

Peshkovskii A. M., Russkii sintaksis v nauchnom osveshchenii, 8th ed., Moscow, 2001.

Petrukhina E. V., Russkii glagol: kategorii vida $i$ vremeni (v kontekste sovremennykh lingvisticheskikh issledovanii), Moscow, 2009.

Plungian V. A., "Vid i tipologiia glagol'nykh sistem,” in: Chertkova M. Iu., ed., Trudy aspektologicheskogo seminara filologicheskogo fakul'teta MGU im. M. V. Lomonosova, Moscow, 1997, 173-190.

Popova T. V., "Peresekaemost' leksiko-semanticheskikh grupp i leksiko-grammaticheskikh klassov slov," in: L. G. Babenko, ed., Russkaia glagol'naia leksika: peresekaemost' paradigm, Ekaterinburg, 1997, 147-239. 
Potebnia A. A., Iz zapisok po russkoi grammatike, 4, Leningrad, 1941.

Rakhmankulova I.-E. S., "K voprosu o teorii aspektual'nosti," Voprosy iazykoznaniia, 1, 2004, 3-28.

Rianskaia E. M., Sposoby deistviia v kognitivnom aspekte, St. Petersburg, 2002.

Shakhmatov A. A., Sintaksis russkogo iazyka, 3d ed., Moscow, 2001.

Shanskii N. M., Tikhonov A. N., Sovremennyi russkii iazyk. Slovoobrazovanie. Morfologiia, 2, Moscow, 1981.

Sharandin A. L., "Sposob glagola kak osobaia formoobrazovatel'naia kategoriia russkogo glagola," in: Funktsional'no-lingvisticheskie issledovaniia, St. Petersburg, 2005, 133-141.

Sheliakin M. A., Kategoriia vida i sposoby deistviia russkogo glagola, Tallinn, 1983.

Sheliakin M. A., Funktsional'naia grammatika russkogo glagola, Moscow, 2001.

Sheliakin M. A., Kategoriia aspektual'nosti russkogo glagola, Moscow, 2008.
Soboleva P. A., "Opyt uporiadocheniia sposobov glagol'nogo deistviia,” in: Aspektual'nye i temporal'nye znacheniia $v$ slavianskikh iazykakh. Materialy zasedaniia komissii po izucheniiu grammaticheskogo stroia slavianskikh iazykov MKS, Moscow, 1983, 46-52.

Soboleva P. A., "Sposoby glagol'nogo deistviia i slovoobrazovatel'nye razriady glagolov,” in: V. N. Iartseva, ed., Slovo v grammatike islovare, Moscow, 1984, 93-101.

Tommola H., “Aspektual'nost' v finskom i russkom iazykakh," Neuvostoliittoinstituutin vuosikirja, 28, 1986.

Varaksin L. A., "Prostranstvennye i neprostranstvennye znacheniia russkikh glagol'nykh pristavok," in: N. K. Florova, S. M. Beliakova, ed., Prostranstvo $i$ vremia $v$ iazyke, iazyk $v$ prostranstve $i$ vremeni, Tyumen, 2005, 139-147.

Vinogradov V. V., Russkii iazyk. Grammaticheskoe uchenie o slove, G. A. Zolotova, red., 4th edition, Moscow, 2001.

Zalizniak Anna A., Shmelev A. D., Lektsii po russkoi aspektologii (= Slavistische Beiträge, 353), München, 1997.

\section{Ильдико Палоши, канд. филол. наук (Pálosi Ildikó PhD) \\ Руководитель Русского центра при Университете им. Лоранда Этвёша H-1088 Budapest, Múzeum krt. 6-8 \\ Magyarország/Hungary \\ palosiildiko@gmail.com}

